MADGU. Mundo, Arquitectura, Diseño gráfico y Urbanismo. NÚM 09, 2022 ISSN: 2594-1208, PP. 01-28

Recibido: 09 de Noviembre de 2020

Aceptado: 06 de Abril de 2021

DOI: https://doi.org/10.36800/madgu.v5i8.78
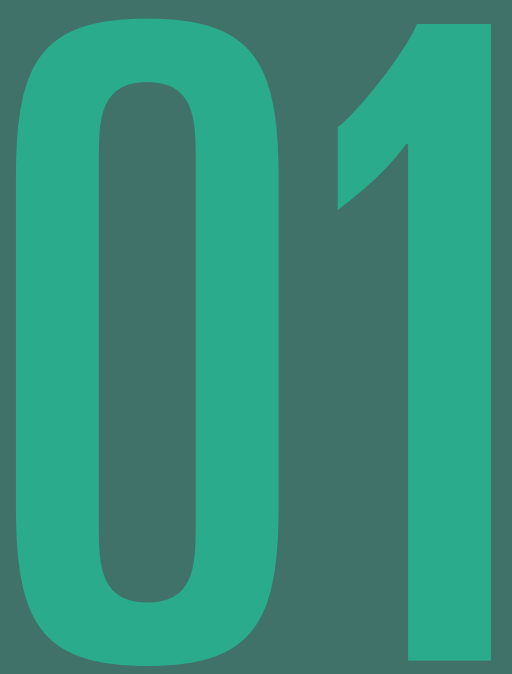

\title{
MATICES DEL ARTE COMO ORÍGENES DE LOS OBJETOS DE DISEÑO MASIVO EN LA SOCIEDAD DE CONSUMO
}

Nuances of art as origins of massive design objects in consumer society

Gerardo Vázquez Rodríguez

gerardo7vazquez@gmail.com

https://orcid.org/0000-0002-7076-8790

Facultad de Arquitectura de la Universidad Autónoma de Nuevo León. Doctor en Arte por la Universidad Autónoma de Barcelona. Maestría en Historia del Arte por la Universidad Autónoma de Barcelona. Arquitecto por la Universidad Autónoma de Nuevo León. 
Palabras clave: Arte y sociedad, Diseño Masivo, Sociedad de Consumo, Historia del Arte. Keyword: Art and society, Mass Design, Consumer Society, Art History

Resumen:

Nuestra sociedad contemporánea a nivel global está afincada sobre un modelo cultural, económico y de producción que se sostiene desde el exacerbado fenómeno del consumo, dando forma a lo que entendemos como Sociedad de Consumo. Esté fenómeno tuvo sus inicios durante la industrialización en todo el mundo, pero sus fórmulas y modelos para acceder a la población generalizada del mundo están reflejados indudablemente en la producción y consumo masivo de los objetos de diseño. En este documento proponemos reflexionar a partir de un aparato teórico cómo es que, desde las enseñanzas y la sensibilidad que el arte propone en el observador, se fue matizando a los objetos de diseño masivo para generar el gran dominio contemporáneo con el que hoy cuentan sobre la sociedad y sus conductas habituales.

\section{Abstract:}

Our contemporary society at a global level is based on a cultural, economic and production model that is sustained from the exacerbated phenomenon of consumption, shaping what we understand as a Consumer Society. This phenomenon had its beginnings during industrialization throughout the world, but its formulas and models to access the generalized population of the world are undoubtedly reflected in the mass production and consumption of design objects. In this document we propose to reflect from a theoretical apparatus how it is that, from the teachings and sensitivity that art proposes in the observer, massive design objects were nuanced to generate the great contemporary domain that they now have over society and its habitual behaviors. 
Gerardo Vázquez Rodríguez

\section{RELACIÓN DEL DISEÑO MASIVO CON LA SOCIEDAD DE CONSUMO}

manera de breve introducción, la relación intrínseca entre la sociedad
de consumo y el diseño masivo, efectos únicos del proyecto de indus-
trialización global, se ha "matizado" permanentemente por diferentes características y condiciones que provienen de circunstancias primordiales del arte. La palabra matiz tiene una gran utilización en las artes: por ejemplo, para los músicos, el matiz es cada uno de los distintos grados o niveles de intensidad o de tempo en que se interpreta una determinada música. Principalmente se distingue entre dos tipos de matices: los matices dinámicos o de intensidad y los matices agógicos o de tempo (De Candé, 2002). En el arte de la pintura, en cambio, el matiz representa el atributo de color que nos permite distinguir entre colores, como el rojo del azul, y se refiere al recorrido que hace un tono hacia uno u otro lado del circulo cromático, por lo que el verde amarillento y el verde azulado serán matices diferentes del verde (Moreno, 2004). La finalidad 
de comparar metafóricamente el matiz con las variantes y añadidos que han sufrido el diseño y la sociedad durante el siglo XX y principios del XXI, es identificar el múltiple abanico de "dinámicas entre colores" e “intensidades" artísticas que han impactado y moldeado de alguna manera la disposición de los consumidores y la caracterización de las piezas de diseño en esta mancuerna formada en la sociedad de consumo, desarrollada desde la primera industrialización hasta nuestros días.

Disgregando ahora sobre una de nuestras temáticas principales, la sociedad de consumo, habituada a la permanente obtención de objetos de diseño para satisfacer necesidades de cualquier índole, es una consecuencia del proyecto de industrialización y progreso, conceptos impulsados en el mundo por medio de la Revolución Industrial. Sobre el inicio de la industrialización, autores como Mark (2007) mencionan que hasta 1750 (antes de la Revolución Industrial) todos y cada uno de los 750 millones de habitantes de la tierra, sin importar dónde residieran o el sistema político- económico que tuvieran, vivían y morían ajustados al antiguo régimen biológico.

Las necesidades de la vida (alimentos, vestido, casa y combustible para calentarse y cocinar) provenían de la tierra, de lo que se podía aprovechar del flujo anual de energía del Sol a la tierra. También las industrias, como las de textiles, de pieles y de la construcción, dependían de productos de la agricultura o de los bosques. Incluso la fabricación de hierro y la de acero, por ejemplo, dependían del carbón vegetal que se obtenía a partir de la madera. Por tanto, el antiguo régimen biológico conllevaba límites no solo para el tamaño de la población humana, sino también para la productividad de la economía. Esta etapa biológica, asentada socialmente durante siglos, no consideraba dinámicas de un consumo y una producción masiva de múltiples requerimientos. Sin embargo, todo esto cambiaría en cien años, de 1750 a 1850, cuando se comenzaron a utilizar cada vez más recursos naturales para el sostenimiento del progreso. El carbón, que principalmente se utilizaba para producir calor, también se empezaría a explotar para impulsar un movimiento repetitivo en las máquinas de vapor (Vázquez, G., 2015). 
La utilización de la energía del carbón en los motores de vapor liberó a la humanidad de los límites impuestos por el antiguo régimen biológico, permitiendo el desarrollo del consumo, de la producción y de la explosión demográfica; esto acrecentaría exponencialmente la formación de emplazamientos urbanos masivos por todo el mundo. A partir de estos fenómenos del progreso se empezaron a movilizar increíbles cantidades de migrantes que abandonaban la vida agrícola para integrarse a la dinámica urbana bajo la promesa de una mejor condición de vida. Por eso surgieron grandes concentraciones urbanas que demandaban servicios públicos eficaces y acordes al desarrollo tecnológico de cada lugar, además de pedir cada vez más productos de consumo para la vida cotidiana.

Para Marks (2007) nuestro estilo de vida actual es posible gracias al inmenso aumento de producción material y de consumo generado por los emplazamientos urbanos ocurridos durante la Revolución Industrial. Estas ciudades instaurarían en sus habitantes un nuevo modelo social asentado en la producción de riqueza, primordial para conseguir el mejor escenario de consumo de bienes y comodidades pertinentes a la nueva vida de las clases sociales en continua mejoría. Esto sería el fundamento básico de la actual sociedad de consumo.

Uno de los principales teóricos sobre las consecuencias de la industrialización y su prolongación hasta nuestros días, Vaclav Smil (2005), considera que el principal momento de formación de la sociedad de consumo se da durante lo que él llama Edad de la sinergia (Age of Synergy), impulso temporal ocurrido en los 30 años previos a la Primera Guerra Mundial, época donde se generó un traslape de civilización entre la población de finales del siglo XIX y principios del XX (Smil, 2005, p.304-306). Este movimiento, que se sustentó a partir del desarrollo vertiginoso de la nueva industria y que reestructuró al recientemente creado mundo de la industria, trajo consigo grandes descubrimientos como: el automóvil, la electricidad y el teléfono, la radio, la televisión y los ordenadores, los motores y el avión, los reactores y los viajes por el espacio, así como las lavadoras y las aspiradoras o la teoría patogénica de las enfermedades y las vacunas, por mencionar solo algunos de los descubrimientos que han trans- 
formado las vidas en todo el mundo. Todas estas innovaciones eventualmente empezaron a ser accesibles al grueso de la población, creando dinámicos patrones sociales orientados al consumo de objetos de cualquier índole.

Cabe mencionar que el excedente de materias primas y los sofisticados procesos de producción industrializados detonaron una masiva producción de objetos de consumo accesibles para todos, consolidando el papel del obrero como nuevo y gran consumidor. "Pero, sin embargo, lo que acabó por consolidar esta variante de alto consumo de objetos, por parte de las masas, fue la aplicación de conceptos estéticos y de distinción aspiracional añadidos a los artefactos de consumo habitual” (Smil V, 2005, p.309). Por lo tanto, la mecanización, en mancuerna con las formas atractivas y accesibles para el consumidor, vendría a transformar los objetos de uso cotidiano; el fabricante acentuaba su capacidad de producir en serie todo aquello que antes era artesanal, sobresaliendo de esta producción las imitaciones de obras de arte y de alto diseño, por las cuales las personas demostraban alta estima debido a su bajo valor, a su rápida factura, su aparente calidad, su reveladora estética y, sobre todo, por la importancia jerárquica de estos objetos que antiguamente solo estaban disponibles para los nobles y acaudalados (Giedion, 1978). Los nuevos objetos de diseño y arte realizados en serie llegarían a ser una importante parte del imaginario aspiracional del nuevo consumidor masivo.

La generación de un exitoso imaginario aspiracional, atractivo para el consumidor masivo, quedó evidente con la conformación de fenómenos como la incrustación de elementos y partes de antiguos estilos nobles ya en desuso, pero que tuvieron mucho éxito en la masa; esto sería uno de los primeros acercamientos masivos al estilo manifestado en un objeto de diseño (Vázquez, 2015). Las máquinas empezaron a producir masivamente estatuas, cuadros, jarrones, macetas, muebles y alfombras; cuanto menos costosa resultaba la producción, más florecían estos adornos. La masa de nuevos consumidores estaba ávida de poseer una referencia significativa de su mejoramiento de vida, y qué mejor forma de hacerlo que poseer un objeto que derivaría en información relacionada con lo que poseían los niveles sociales de la aristocracia. Hasta cierto punto el objeto de diseño de esta época y su simulación acortaban, al menos 
ideológicamente, las grandes brechas sociales. El consumo de objetos en la época industrial definía con estas dinámicas aspiracionales algunas de las ideas que persisten hasta nuestros días bajo el fenómeno del diseño y el consumo.

Para autores como Bourdieu (2015), González Ochoa y Torres Maya (2012), hasta antes de la industrialización los objetos de la mayoría de la población del mundo carecían de una propuesta estética que fuera intencionada para lograr una distinción de entre los demás objetos similares y que pudiera logar la apropiación por parte del usuario. Así, el objeto que surge desde la Revolución Industrial trataba de modificar sus principales intenciones artesanales y funcionales. También, en referencia al proceder de la masa sobre el consumo de objetos y el cuestionable valor de estos que enaltecen la simulación de la jerarquía social poblacional, Walter Benjamin (2003, p. 4) mencionaría "estriba éste en dos circunstancias que a su vez dependen de la importancia creciente de las masas en la vida de hoy. A saber: acercar espacial y humanamente las cosas es una aspiración de las masas actuales”.

De esta forma, los obreros de las primigenias urbes industriales se acrecientan como consumidores a raíz de un escenario con excedentes de materias primas, nuevos procesos de producción mecanizados y, especialmente, por la gran atracción que les suscitaban las características del objeto dentro de su afán aspiracional. Por lo tanto, durante todo el siglo XX la mayoría de la población mundial empezó a invertir disciplinariamente su tiempo en jornadas de trabajo que le redituaban en un salario, el cual le permitía acceder al fascinante $\mathrm{y}$ algunas veces irreal mundo de los objetos de diseño masivo.

Desde los inicios de la Revolución Industrial a mediados del siglo XIX, el diseño masivo y de alto consumo se vio principalmente favorecido e impulsado en sus discursos y sus características por improntas que se venían gestando desde el ámbito de las artes. Si bien la plataforma inicial del diseño para ingresar al mundo de la modernidad fueron lo artesanal y sus altas características funcionales, postulamos que esto fue rápidamente superado en la medida en la que el consumidor masivo estaría impulsado a adquirir artefactos principal- 
mente basado en sus características estéticas y simbólicas, peculiaridades que estaban relacionadas en muchos de los casos con la sensibilidad artística del momento. En este marco temporal de la industrialización, el arte llegó a crear una escala social compuesta por imágenes y representaciones tan cercanas a la masa, que lograron sensibilizar a la población ante discursos conceptuales y estéticos que serían después simbolizados y matizados por los objetos masivos. La repercusión de ver discursos artísticos populares en los objetos de uso común impulsó en muchos de los casos distinciones entre productos, las cuales se verían consolidadas en patrones de consumo de productos.

Para autores como Benjamin (2003), el arte, con la reproductibilidad de la industrialización, rompía así su aura de élite y conocimiento perpetuo para contaminarse ante las dinámicas del objeto maquinado. Por lo tanto, durante esta época, los objetos que destaquen en su estética y su simbología aspiracional podrían ser más poderosos y notorios para la masividad que cualquier otro artefacto con una alta función o de corte artesanal. Como apunte a esta premisa, la evolución de esta idea es la que llevaría a generar los inicios de la ingeniería social de propaganda (Hayek en McElroy, 1998) y que tiempo después desembocaría en la publicidad y el marketing contemporáneos. Indudablemente esto daría pie al formato de diseño en la actualidad, donde tanto la función y la estética se ven supeditadas a la información que declara y comunica el objeto (Vázquez, 2015; González, 2012; Normand, 2005). Por consiguiente, la sensibilidad del consumidor urbanita de principios de la industrialización se ve conformada principalmente por cuestiones de una estética aspiracional.

Desde la antes mencionada escala que formó el arte de la época industrial es posible reconocer su tendencia a la cercanía con la población, lo que ayudaría a desarrollar el matiz del objeto de diseño; como resultado el fenómeno artístico se transformaría radical y rápidamente. Esta metamorfosis se consolidaría bajo permanentes ideologías de cambio social y sobre el rompimiento de pensamientos convencionales de la realidad. El arte modificaría en está época tanto sus principios técnicos tradicionales como los conceptuales. En muchos casos 
las herramientas del arte, en conjunto con más elementos sociales, lograrían innovar la interpretación que se tenía de la realidad a nivel social y masivo, y como ejemplo de esto surgirán las llamadas vanguardias artísticas.

Las vanguardias artísticas, de origen europeo y de propagación subsecuente por el mundo occidental, tendrían su umbral de origen en los pintores impresionistas, quienes manifestarían técnicas y discursos radicales respecto a lo considerado como establecido para su época (Gombrich, 2010). Menciona Vázquez (2015) sobre los inicios del impresionismo:

Por primera vez en la historia moderna, pintores como los impresionistas se permitirían el uso de una estética y de un discurso cercano a la colectividad y a los gustos de la masa, este grupo de artistas no consideraba al arte como un fenómeno estimado y destinado solo para el entendimiento de un pequeño grupo poblacional perteneciente a la elite en el poder o entendido solo por un grupo de especialistas. (p.46)

Esta ideología de un acercamiento desde el arte a la masa social sería lo fundamental para las vanguardias, ya que no se consideraban artes de la élite sino provocadoras de la población (Gombrich, 2010). Esto generaría toda una revolución en la capacidad de apreciación de la realidad por parte de las personas; se sensibilizó al pueblo como interesados de lenguajes artísticos. El arte impactó fuertemente a la nueva sociedad industrializada y generó efectos considerables sobre las conductas masivas.

Ejemplo de lo anterior son los inicios del movimiento feminista y sufragista europeo durante las primeras dos décadas del siglo XX. Por medio de primitivos performances, carteles y gráficas posicionados como los primeros rastros del arte urbano, estos inicios del arte feminista desembocarían rápidamente entre los años 1918 a 1921 en los primeros votos de la mujer en países como Austria, Inglaterra y Alemania (Alario, 2008). A su vez, el movimiento Dada incidió en la sociedad como gestor de los ideales del romanticismo y fue iniciador de un modelo de mundo basado en la promulgación de una juventud nihilista en experimentación y en el fomento al llamado mundo del espectáculo 
(Granés, 2011). También el constructivismo ruso de Lenin se utilizó para sensibilizar a toda una población y generar un imaginario de país por medio de la propaganda artística y de diseño que se distribuía a través de los llamados trenes y barcos de agitación. Posteriormente, al consolidarse la Unión Soviética, la valía de la caída de los Zares y la llegada del progreso se promulga desde majestuosos proyectos de arte y diseño, como el proyecto de edificación de la Torre de Tatlin de 1920 (Valmaseda, 2011 y Clark, 2000). El diseño de este artefacto arquitectónico contaba con una aparatosa estética, exacerbado simbolismo y poca funcionalidad.

Otra vanguardia de alto impacto fue el llamado futurismo italiano: este cimbró las bases de la sociedad industrial al tratar de reivindicar de manera tajante el nacionalismo y la clase obrera del país. La declaración del Manifiesto futurista (1909) y la promulgación de su estética revolucionaría generaron lineamientos importantes para el pensamiento europeo y gran parte del mundo occidental. Marinetti y su visión futurista más adelante generarían ideales fascistas, pero también forjarían una estética que dio pie a corrientes de diseño como el art déco ${ }^{1}$. A su vez, el arte expresionista alemán de la posguerra reivindicaba la valía del terror vivido por toda una sociedad mundial y la sensibilidad del ser humano ante los peores hechos de la historia conocida. La estética y la temática promulgadas desde este estilo cambiaron por completo la formación del recién creado cine; las primeras películas que nos hablan de dominación social (Metrópolis, 1927) y de peligrosos monstruos y quimeras (El gabinete del doctor Caligari, 1920; Nosferatu, 1922 y El Gólem, 1920) surgen durante este periodo.

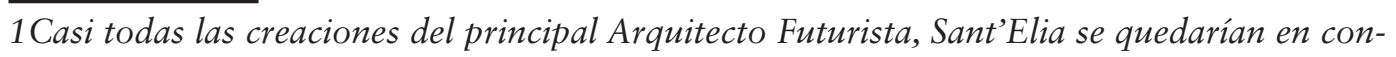
cepto, poco de su obra se construyó, pero años más tarde sus propuestas de diseño fueron influencia directa para obras públicas a nivel mundial. El art déco fue el estilo arquitectónico donde más se acentuó囚 esta influencia del futurismo. El estilo art déco, preponderante en la arquitectura y el diseño, se caracterizó por sus formas alargadas que trataban de imitar los vértigos de una velocidad propuesta ante el observador; este estilo fue considerado como parte del futurismo y se desarrolló principalmente en las décadas de 1920 y 1930. El nombre original tanto para el art déco temprano como para el tardío fue Art Moderne; el nombre final no fue utilizado sino a partir de 1968, cuando el crítico de arte inglés Bevis Hillier inventó el término. (Cabello Gallego, S. 2015). 
El arte desarrollado por las llamadas vanguardias artísticas ayudó a conformar un importante imaginario social y estético, el cual impulsaría representaciones y símbolos que moldearían a toda una generación de pobladores de los nuevos escenarios industriales. Esta masividad poblacional ahora confrontada a las vanguardias artísticas de finales del siglo XIX y primera mitad del siglo XX, como nunca antes en la historia, acrecentaría su visión del mundo por medio de recursos estéticos y simbólicos procedentes desde el arte.

Durante la segunda mitad del siglo pasado nuevas formas de expresar el arte dominarían el mundo, acercándose de nuevo a la población masiva. Para Marks (2007), después de las dos grandes guerras mundiales sobresalió un gran triunfador, los Estados Unidos de América, cuyos ciudadanos/artistas rápidamente "aprendieron de las experiencias europeas sobre la gestión y la creación de iconografía cultura con fines de propagar imaginarios hegemónicos en la cultura de la población mundial” (Stonor, 2001, p. 160).

La época subsecuente a las guerras mundiales fue una disputa por la jerarquía mundial entre los EUA y la Unión Soviética. Esta coyuntura conocida como Guerra Fría sería para autores como Stonor (2001) el gran escenario de la conquista cultural llevada a cabo por medio de la iconografía estética. Los norteamericanos lograrían establecer toda una estructura gubernamental e institucional que eficientemente pudo crear una instrucción masiva a modo para sus fines de expansión cultural. Lo dominante dentro de esta propuesta sería la iconografía artística y de diseño, propagada e impulsada por grandes instituciones museísticas, educativas y de comercio cultural. En cambio, debido a medios como el cine y las bellas artes en general, se promulgó esta conquista cultural en la cual la modalidad favorita para expresar estas representaciones culturales serían los objetos de consumo masivo (Stonor, 2001).

El mundo se inundaría de objetos de uso común que estaban matizados desde las representaciones artísticas del arte norteamericano. Ejemplo de esto es la producción, tanto en arte como en diseño, de autores como Warhol, quien participó en diseños de moda, portadas discográficas, muebles y campañas publicitarias (Printz y King-Nero, 2010). Roy Lichtenstein, por su parte, 
participó en diseño de mobiliario, plazoletas públicas, diseño gráfico y de interiores (Fundación March J, 2007). Jackson Pollock, a su vez, presentaría una estética que ha sido abordada inmediatamente por múltiples autores de diseño de modas, gráficos y de mobiliario (Ruiz N., 2020). Además, Jasper Johns y su estruendosa utilización de la bandera norteamericana fue el parteaguas para el uso frecuente de dicho estandarte en todo tipo de representaciones de uso común (Lampkin, 2017). Finalmente, tiempo después llegaría el fenómeno de Jean Michell Basquiat, quien impulsó el uso de sus pinturas como un rico contenido para la producción de una estética del arte urbano en múltiples objetos de diseño de uso diario (Navarra, 2000 y Sánchez, 2018), entre otros más autores de la influencia norteamericana de la segunda mitad del siglo XX.

Si bien durante la época de las vanguardias artísticas europeas los objetos de diseño que mayor matiz atenuaron desde el arte fueron edificios, afiches propagandísticos y conceptos urbanos y de cinematografía, durante la última mitad del siglo pasado la comercialización del arte norteamericano impulsó el matiz del arte en casi todos los objetos de uso habitual para la población masiva. En general la fórmula de acercar el arte a la sociedad daba como resultante la matización y transformación de los objetos habituales de diseño desde la iconografía artística, esto como parte de una promulgación de un imaginario dominante y efectivo para generar tendencias de consumo.

Por lo anterior, para que la masa poblacional empezara a manejar términos estilísticos y artísticos en su vocabulario habitual e imaginario constante, ocurrió una aproximación de las artes hacia los observadores de la población generalizada. Contrario a lo que podría suceder hace apenas unos cien años, hoy la sociedad contemporánea está acostumbrada al manejo básico de discursos estéticos. Actualmente la mayoría de la población occidental podría reconocer una simplificación de formas como el minimalismo en un objeto, o el extremo de la saturación, barroco, incluido también en un diseño. 
Distinguir y sensibilizarse a las formas con la idea primordial del consumo por medio de la selección estilística de objetos no siempre fue una característica de la masa poblacional en el mundo occidental. En gran parte la sensibilidad que hoy manifestamos por la estética, el gusto artístico y la distinción se da en relación con nuestra permanente convivencia con objetos cargados de esta información estilística. Como apunta Portero (2001) en su trabajo sobre cultura y propaganda, durante la primera mitad del siglo XX, con fines de consumo, se sensibilizó a la colectividad para desarrollar principios básicos de apreciación estilística dentro del discurso estético incluido en el objeto contemporáneo de arte y diseño. Obligatoriamente la relación entre el diseño masivo y sus consumidores ha presentado a lo largo del tiempo una gradación variada e intensa en sus relaciones. Como evidencia de lo anterior, diferentes situaciones y sofisticaciones han añadido complejidad a esta situación, creando en los objetos nuevos estilos, nuevas formas, nuevas funciones por parte del diseño, nuevas vías de comunicación. También, por parte de los individuos, se han gestado permanentemente nuevos comportamientos de consumo, de necesidades, de comunicación, de expresión y de significación. Y posiblemente uno de los principales componentes que ha servido para mantener viva esta correspondencia entre sociedad y diseño han sido la creciente sensibilidad a la estética propuesta por el arte y sus circunstancias arduamente afincadas en múltiples objetos de uso común y habitual.

\section{EL ESTILO ARTÍSTICO COMO MATIZ EN LOS OBJETOS DE CONSUMO}

Una de las principales circunstancias que matizan la relación del arte con el diseño sería la cuestión del estilo. En el presente, un estilo artístico se valida y toma importancia colectiva al lograr una mayor unificación de criterios de los individuos sobre la coherencia y pertinencia de dicho estilo dentro de un sistema de consumo compatible con factores de vida de los propios individuos. Sin embargo, no se valida el estilo artístico únicamente por su manufactura o idea propuesta: si el estilo artístico logra impregnar información coherente y reconocible por parte del sistema de individuos, entonces será fácil su aceptación y propagación. 
El estilo artístico se ha vuelto el matiz primordial para el discurso del diseño contemporáneo y resulta un elemento fundamental de las características del propio producto. Difícilmente podríamos negar que la estética contenida en la forma es siempre la primera cualidad leída por el usuario frente al objeto; en cambio, la forma de entender y organizar dicha estética será siempre el punto inicial de la propuesta estilística de cualquier objeto de diseño masivo. Hatje (2005) menciona: solemos llamar “estilo" (en el sentido de "estilo de época”), justamente, a este fenómeno que consiste en que cada época artística posea un lenguaje formal común. Esta postura atiene también al diseño a partir de su proceso de consumo masivo, pues se crean importantes vínculos con el arte y sus características. La lectura y el acoplado del diseño con un lenguaje estilístico basado en el arte se impulsan desde los formatos educativos por los cuales se enseña todo el diseño; los estudiantes del diseño aprenden a ordenar sus ideas y sus modelos creativos a partir de iconografías que se desprenden desde la historia del arte.

El lenguaje estilístico formal tiene una fuerza y una presión tales, que se puede hablar de una dominación estilística durante diferentes periodos de la historia. Muchos diseños innovadores de una época no pueden ser asimilados fácilmente por los mercados de consumo debido a la disparidad que pueden presentar ante los otros diseños que habitan la misma época y dominan la percepción del consumidor. Por lo anterior, innovar un nicho de consumo con un objeto de diseño revolucionario puede ser complicado si antes no se revisan las posibilidades de percepción que tendrá el usuario sobre él. Es necesario que el objeto pueda mantener un lenguaje de formas y funciones parecidos a lo existente en su época; al menos esta premisa funciona para su éxito en el consumo masivo.

La presión de un estilo dominante en un tiempo determinado es tal que acabará sometiendo otros intentos de expresión que pretendían algo muy diferente. Aun así, eventualmente se dan transformaciones radicales en los estilos por un acontecer casi masivo de muchos objetos de diseño que promulgan formas parecidas y se vuelven a establecer como una hegemonía. Por ejemplo, el excesivo racionalismo arquitectónico y urbanístico que ocurrió 
de lleno en la Europa de la posguerra, y que se extendería por varias décadas en gran parte del mundo occidental, poco fue pasmado en un largo periodo de tiempo, aun cuando sus detractores empezaron temprano las críticas y las propuestas adversas al exceso de racionalidad en la forma y la función (Jacobs, 1961; Lefebvre, 1968 y Virilio, 1978,). Sería tan dominante el racionalismo de autores como Le Corbusier que sus formas y conceptos impregnaron todo lo que quedaba del siglo XX y aún en 2021 sus formas siguen siendo de las más utilizadas, al punto de que han reprimido muchas propuestas que tendían más a la exacerbación de las formas y al manierismo. Fuchs (2005) compara la dominación estilística con un proceso semejante al que observamos en el desarrollo de la lengua, donde el intento infantil de crear una propia y única expresión de lenguaje queda absorbido, necesariamente, en las formas ya preestablecidas del lenguaje dominante. Así, toda palabra o forma gramatical nueva resulta automáticamente descartada por las anteriormente prefijadas.

El intento personal acaba generalmente en una forma preestablecida, y solo es posible en una situación concreta y determinada (Hatje U., 2005). Esto lo acota también Fuchs en Hatje (2005) y lo expresa por medio de la frase: "No todo es posible en todo tiempo". El problema del estilo se complica cuando el estilo personal de un artista o diseñador intenta diferenciarse de lo general de su época, e incluso hasta cierto punto contraponerse a él. El creativo puede responder de un modo matizado, más o menos personalmente, a las cuestiones que constituyen la norma en su situación concreta y determinada. Tanto el diseñador como el artista logran así su propio y peculiar estilo en contraposición a lo establecido y con lo cual se compite.

La idea del diseño, a partir de la industrialización, se manifestó como un fenómeno que no solamente estaba formado por materiales y sustentado solo en lo funcional y con fines herramentales. También se empezó a explorar la idea de comunicar un discurso o manifestar un concepto estilístico, y que este contenido pudiera estar implícito en la lectura de sus formas y propiedades estéticas, así como en la lectura de sus condiciones de usabilidad y en la lectura del propio entorno cultural. Todo lo anterior empezaba a suceder bajo la distinción o el gusto del observador en cuestión: empezaba a surgir el gran 
público consumidor. Para Vázquez (2015 y 2019) este perfil de consumidor fue formado desde la promulgación cultural de una apurada inercia de progreso social y adoctrinamiento hegemónico por los imaginarios estéticos de la ingeniería social y publicitaria del siglo XX.

Anterior a los tiempos de la industrialización, el objeto de diseño de corte artesanal contaba principalmente con un uso común y de términos principalmente herramentales; solo se le concedían propiedades estilísticas y de discurso a los objetos que se consideraban como objeto de arte o de alta artesanía simbólica (Vázquez, 2015). Es decir, el objeto de diseño con consumos masivos, como los tiene hoy en día, no contaba con una experiencia estilística ni nada parecido. Más bien, al menos esta experiencia estética no era planeada ni determinada por el diseñador. En el mejor de los casos esos objetos eran desarrollados por un artista o un artesano; de esta forma, los objetos de alta carga simbólica eran principalmente reservados para uso exclusivo de la alta sociedad e intelectuales y principalmente se le refería como arte.

Era difícil, o casi imposible, encontrar objetos de uso masivo con características estilísticas constantes antes de la producción en serie que alimenta el alto consumo que se da a partir de la industrialización y que después se acrecentaría desde la Segunda Guerra Mundial. Por lo mismo, a nivel cultural no se podría hablar de un estilo predominante en el uso del diseño antes de la industrialización. Este planteamiento de objetos cargados de estética, y su consecuente impacto ante el espectador por medio de una carga estilística, no sería del todo nuevo. De hecho, casi todos los grandes creativos de las principales épocas iconográficas del arte ya habrían entendido este poder implícito en las formas del objeto y de la imagen. Sin embargo, este cometido de comunicar ideas, discursos o creencias a un nivel colectivo y de gran alcance en la población era una nueva forma de intervención social y cultural por medio del objeto de uso común, ya que esta tendencia nunca había ocurrido con tanta magnitud como sucedió a partir de la modernidad industrial.

Las anteriores condiciones fueron añadiendo singularidades al objeto de diseño; estas distinciones y particularidades fueron significando a partir de los inicios del siglo XX una restructuración, tanto para las escuelas de diseño 
como para los diseñadores. El escenario del diseño ahora empezaba a estar conformado en igual importancia tanto por un esquema de función como por uno de organización estética propuesta en sus formas y caracteres de significación, lo cual favorecería el uso del estilo en el objeto. Función y estética, ambas relacionadas, comunicaban ideas y conceptos propuestos para los usuarios. En consecuencia, el estilo, al ser un discurso contenido en el propio diseño, sería un nivel emergente de la combinación y matización de la forma y la función, aunque primordialmente está más relacionado con las cuestiones estéticas.

Bajo este nuevo esquema estilístico de orden estético y comunicación simbólica propuesto para el nuevo diseño masivo, las principales escuelas de la época industrial empezaron a relacionar el fenómeno del diseño de objetos con materias como el arte, la filosofía, la comunicación de masas y la estética. Para estas primeras escuelas se volvía importante distinguir cuáles serían los discursos de estilo que harían distintivos ante el usuario a los objetos de consumo masivo y que, además, propondrían identidad al mismo objeto en comparación con otros. Así iniciarían las primeras marcas y sus sellos estilísticos.

Como resumen de lo anterior, el arte había acrecentado desde épocas muy remotas la idea de la comunicación de conceptos, ideas y discursos por medio de características establecidas en las obras. En particular, los estudiosos de la materia determinaban estas características como un estilo o corriente; así, al retomarse por parte de los diseñadores y de las escuelas de diseño los planteamientos del arte sobre el hecho estilístico, es que se empieza a transformar el objeto de diseño. A partir de esta época el diseñar se relaciona en gran medida con el fenómeno de estudio y producción que tendría parte de su origen en la historia del arte, todo por medio del hecho estilístico. El diseño retomará para su aproximación al estilo la experiencia acumulada dentro de la historia del arte.

Es tanta la cercanía que se da entre lo artístico y el diseño durante la industrialización y durante la época postindustrial, que se marcaría el inicio para que ambos proyectos, el artístico y el de diseño, compartieran las mismas 
nomenclaturas estilísticas. Así, las vanguardias histórico-estilísticas del siglo $\mathrm{XX}$, como el futurismo, el constructivismo, el expresionismo, el fauvismo o el neoplasticismo, entre otras, encontrarían definición tanto en obras de arte como en objetos de diseño de todas las escalas.

El aprovechamiento de los recursos estilísticos y artísticos en el diseño ha sido subrayado especialmente por un estrecho vínculo con la publicidad. La publicidad establece en el consumidor discursos e imaginarios deseables que tendrán que verse reflejados en el contenido de forma y función del objeto. El compendio de ideas que la publicidad establece en el usuario contemporáneo jerarquiza información en los procesos mentales del usuario; en otras palabras, genera deseo y aspiración. Entonces tanto la forma como la función del objeto quedan supeditadas para la estructuración y cumplimiento de tal o cual imaginario creado por esta información inducida tanto en el individuo como en la colectividad.

Claramente la publicidad ha sacado provecho de la sensibilidad innata que tiene el ser humano para generar reflexión frente a una obra de arte. Por ejemplo, el color, la textura, la luz, el discurso y todas las propiedades contenidas en una obra artística generan, por su simple exposición al observador, un compendio de manifestaciones e incidencias en el imaginario propio; es así como la publicidad ha sido en gran parte una divulgadora de estilos artísticos consumidos por la masa. Al fin y al cabo, el discurso publicitario se ha encargado de impregnar de valores artísticos al objeto y de revestirlo de sensibilidad artística.

La acentuación tanto del arte en el objeto de diseño como del arte como elemento primordial del discurso publicitario han sido los dos principales precursores del impacto que el mismo arte ha logrado sobre la masa poblacional. Como efecto de lo anterior, el conocimiento del arte en la colectividad se ha difundido en el último siglo por medio de los canales de consumo que lo utilizan como herramienta clave de distinción. Así, el mismo poder de la élite capitalista y productora de la Revolución Industrial se ha sofisticado al utilizar el arte como un medio de manipulación sobre los patrones de consumo. Dicho de otra forma, el arte se ha transformado en un canal por donde 
viaja el discurso de poder prioritario: este poder y su mensaje se almacenan en las formas y funciones del diseño y al final los consume la colectividad. No hay que confundirse y pensar que por esto la masa poblacional se habría vuelto experta en un arte elevado y sus manifestaciones estilísticas, pero sí es evidente que se ha sensibilizado a los matices del arte masivo y generalizado que se dan por medio del diseño y la publicidad. Los artistas y su producción han alimentado durante el último siglo el lenguaje del consumo masivo; en otras palabras, los expertos en diseño y publicidad recurren a las posibilidades artísticas para distinguir sus propuestas ante el consumidor.

Valéry (2019) realizó en los años treinta una promulgación visionaria sobre nuestros tiempos; menciona sobre el futuro del arte y del diseño:

De entrada, indudablemente, sólo se verán afectadas la reproducción y la transmisión de las obras. Se sabrá cómo transportar y reconstituir en cualquier lugar el sistema de sensaciones o más exactamente de estimulaciones que proporciona en un lugar cualquiera un objeto o suceso cualquiera. Las obras adquirirán una especie de ubicuidad. Su presencia inmediata o su restitución en cualquier momento obedecerán a una llamada nuestra. Ya no estarán solo en sí mismas, sino todas en donde haya alguien y un aparato. Ya no serán sino diversos tipos de fuente u origen, y se encontrarán o reencontrarán íntegros sus beneficios en donde se desee. Tal como el agua, el gas o la corriente eléctrica vienen de lejos a nuestras casas para atender nuestras necesidades con un esfuerzo casi nulo, así nos alimentaremos de imágenes visuales o auditivas. (p.131)

Tomando en cuenta la afirmación de la cita, el consumo ha sido, en muchas formas, el camino que se ha marcado para cumplir esta promesa sobre la intensa dinámica de la obra de diseño y la cuestión artística. Los diseños destinados a un alto impacto masivo, situados en un mercado global, constituirían un discurso y un significado de poder tanto o más importante que algunas instituciones gubernamentales o públicas que están solo restringidas a sus pueblos o regiones. Habría que ponderar el peso real del discurso estilístico y la información que puede propagar e imponer un objeto sobre la sociedad, pues existen objetos de consumo masivo que podrían alcanzar hasta niveles 
totalitarios de impacto y comunicación sobre la población mundial. Estos objetos, por lo anterior, marcarían una gran influencia en el pensamiento y actuar de la población.

\section{EL PROCESO DE OBSERVACIÓN Y ASIMILACIÓN DEL ARTE COMO MATIZ PARA EL DISEÑO MASIVO}

Menciona Anne Cauquelin (2015) sobre lo que se observa desde lo artístico:

El arte permitiría ver la manera por la cual lo visible se presenta a nosotros, es decir, lo que es el mundo; sería entonces el medio privilegiado para pensarlo y hablar de él. Es en y por las obras que el mundo devendrá visible. (p. 88)

De ahí se desprende que la naturaleza del arte es mostrar, por medio de sus recursos, nuevos y posibles mundos ante el ojo del observador; en consecuencia, la asimilación de estos recursos por parte de múltiples observadores cumple la función de formar vínculos entre dichos espectadores. Estos vínculos son sujeciones colectivas entre los individuos; lo vinculante les propone discursos que se vuelven interpretaciones sociales generalizadas desde las formas, emociones y representaciones que se les propusieron por medio de la obra de arte. La cualidad para que algunos vínculos sean más sólidos, mejor recibidos y almacenados en la colectividad, transitaría por el filtro de aceptación emocional de los observadores ante la obra artística (Higuera, Llinares y Macagno, 2021).

Lo que más impacta a un observador es la alta estimulación de sus emociones por medio de metáforas, recuerdos o propuestas que son reconocibles e interpretadas por quienes observan; estos elementos impactan y se almacenan entre toda la cognosis y corporeidad de los individuos. Indudablemente, cuando los individuos interiorizan el discurso artístico propuesto por una obra lo integran a su ser y subsecuentemente se vuelve posible reconocerlo en otras obras similares, al menos de manera subjetiva. Sin embargo, también es posible que el reconocimiento ocurra hasta conscientemente (Ishai, A., Fairhall, S. L. y Pepperell, R. 2007). A su vez, también existen discursos similares en otras obras de arte que por medio de sus elementos de representación estimulan el 
recuerdo de lo asimilado anteriormente. A mayor estimulación colectiva por parte de la obra de arte, habrá mayor vinculación social entre individuos, lo que se traduce en mayor asimilación de un discurso con coincidencias colectivas; el resultado es que se propician discursos colectivos que nos habitan, y por los cuales aprendemos permanentemente a interpretar la realidad. Indudablemente lo anterior nos llevaría a crear patrones de comportamiento ante los demás y ante el sistema de objetos que nos rodean, ya que se crean distinciones, preferencias, gustos y comportamientos en la colectividad (Vázquez, 2013). Por ejemplo, una de las más bellas obras de arte de Miguel Ángel Buonarroti, la llamada Pietà, o La Piedad (1498-1500), de exhibición permanente en el Vaticano, genera el impacto de asombro por una innovadora representación de la muerte de Cristo y la reacción de la Virgen María. Semejante imagen estimula en gran cantidad de observadores un alto discurso emocional: la escena de la defunción de un hijo y la reacción de su madre es fácil de leer (percibir)² y ligar a nuestras emociones más profundas; las formas y la genial ejecución de la escultura impiden quedarse imperturbables ante esta representación.

La estimulación y el discurso creado en cada observador por medio de la obra nunca es idéntico al de alguien más, pero este discurso sí cuenta con valiosos puntos de coincidencia entre quienes hayan observado la pieza. Estas coincidencias en la asimilación discursiva de la representación son los puntos primigenios de la vinculación entre un grupo de observadores que se expuso a la pieza. Subsecuentemente a esta exposición a la Piedad, los observadores podrán ser más sensibles al reconocimiento del discurso emocional asimilado cuando contemplen otras piezas con reminiscencias, formas o información similar. Esta significación de la pieza de arte como vínculo colectivo ha sido ampliamente aprovechada para impregnar discursos de alto impacto que conllevan una información determinada en objetos de diseño de uso común. Retornando al ejemplo de la Piedad, esta pieza ha sido un gran impulsor para

2 Gombrich E. H (2010, p. 54) menciona sobre la identificación: Hemos visto que la lectura de una imagen, como la recepción de cualquier otro mensaje, depende del conocimiento previo de las posibilidades; solo podemos reconocer lo que ya conocemos. No podemos lograr que nuestra mente aísle (situaciones), debido a nuestros conocimientos anteriores. 
impregnar en la colectividad la información sobre el culto a la Virgen María; con el tiempo se volvería el ícono perfecto de la benevolencia que se buscaba expresar desde la conceptualización católica de la madre de Cristo.

Imaginemos este ejemplo que expone al arte como algo que propone nuevos mundos y vincula sociedades: como primer punto, a lo largo del proceso de industrialización y de consumo masivo, la población fue expuesta a manifestaciones artísticas como nunca antes en la historia del mundo conocido. Inicialmente sucedió con propuestas radicales de pintura, escultura, arte conceptual y los primeros indicios artísticos del performance y el arte urbano. Subsecuentemente el cine se volvió una importantísima amalgama de todas las artes, ya que debido a su alto impacto masivo se propagó sin parar por todo el mundo. Después llegaría la televisión: indudablemente las producciones de entretenimiento y drama en este medio fueron influenciadas por el cine y por todos los preceptos artísticos anteriores a su época. Estas producciones podrían considerarse instrumentos de sensibilidad artística que están orientados principalmente al rápido impacto y reconocimiento emocional de la gran mayoría de la masa poblacional. Por lo tanto, los discursos que presenta son muy elementales, pues tienen el afán de ser fácilmente entendidos por la gran mayoría de las personas; entonces nuestras mayores coincidencias como grupo dispar se dan en el entendimiento del mundo por medio de los conceptos menos intelectuales. Por su parte, el cine comercial y de gran difusión masiva se apega a las mismas condiciones que la televisión, pero indudablemente esto conllevó a que la música fuera la mayor de las artes masificadas, ya que nuestras vidas se musicalizaron a la par de vaivenes estilísticos muy variados. Así, cada grupo generacional de los últimos cien años creó y enalteció un artefacto musical que acompañaba la promulgación de ideas y generaba todo un vínculo generacional. Empero todo esto, aunque el anterior ejemplo intenta narrar de manera muy breve el desarrollo del arte y su creciente acercamiento a la mayoría de la población durante los últimos años, esto no estará completo sin el entendimiento de que el verdadero portador de la información que el arte propaga, se establece desde la información que revela el objeto de diseño común y habitual. 
El artefacto de diseño asimila la estética, el estilo y la información sugerida por los artistas e ingresa de manera más habitual y contundente a la percepción y el uso de la mayoría de la población. Por ejemplo, Andy Warhol y su propuesta de pop art es realmente significativo por el alto consumo que se produjo de objetos de diseño que fueron matizados desde sus obras artísticas. El concepto artístico del pop art fue impulsado por el uso de los objetos cotidianos inspirados en él; además, el artefacto de diseño también se volvería un distintivo por medio del aprovechamiento de discursos artísticos innovadores.

Por lo anterior, el siglo XX fue el gran momento de sensibilización poblacional masiva al mundo de las artes y supuso la gran promulgación de discursos de impacto por medio de la representación estética; nunca habían existido grupos generacionales tan sensibles a los discursos artísticos. La formación de gustos y distinciones estéticas entre grupos poblaciones sin una educación profesional de las artes nunca fue tan clara y evidente. Sin embargo, este proceso requirió de constantes objetos de consumo que representaran el mundo de las artes masivas ante los ojos de las grandes audiencias.

El diseño aprendió rápidamente a integrar dentro de su comunicación los diferentes estilos y propuestas que eran esperados y demandados por la sociedad y su consumo. El diseño aprendió también a ser el vínculo poblacional y habitual en la vida de todos: ya no era necesario asistir a un museo para convivir con las obras de nuestro artista favorito; ahora podíamos contar con una reproducción de su obra o un recuerdo de sus piezas de arte en una taza de café. Las vinculaciones con nuestras historias favoritas de cine o televisión se daban por la cantidad de objetos que se podríamos coleccionar o incluir en las actividades diarias de nuestro acontecer.

\section{CONCLUSIÓN}

Como conclusión, podríamos afirmar que el arte ha sido el matiz clave y fundamental para llegar a la percepción actual que tenemos acerca del objeto de diseño y detonar así la gran sensibilización en la que estamos envueltos hoy hacia el mundo de los objetos. El arte expuesto a la masificación modificó circunstancias de percepción de la realidad por parte del observador y, bajo la perspectiva de sus cambios, permitió la existencia de un nuevo objeto de 
diseño, uno en el cual se manifestaban los principios de belleza como parte del nuevo discurso del diseño. En muchos de los casos las artes fueron el crisol fundamental para la manifestación de los acuerdos entre diseño y sociedad.

El estilo y las cualidades de comunicación y vinculación de las bellas artes han matizado al objeto de diseño. Primeramente lo hicieron desde mediados de la Revolución Industrial y después se evidenciaría aun más esta matización a partir de los inicios del consumismo después de la Segunda Guerra Mundial. Las bellas artes de élite, que durante mucho tiempo fueron resguardadas para un selecto grupo, se disolvieron rápidamente en las formas y funciones de los objetos de consumo; ahora era común encontrar las artes estilísticas de los museos replicadas en objetos de alto consumo que perseguían y tenían como objetivo primordial el consumo por parte de la masa.

La población actual del mundo tendría desde inicios del siglo XX un consumo acelerado de las bellas artes, pero enmarcadas bajo los cánones de la publicidad y el diseño de objetos. Hay que cuestionar el mundo de consumo que el diseño, desde el arte, ha traído consigo a una sociedad ávida de vinculación colectiva.

\section{REFERENCIAS}

Alario Trigueros, M. (2008). Arte y Feminismo. San Sebastián: Editorial Nerea.

Benjamin, W. (2003). La obra de arte en la época de su reproductibilidad técnica. México: ítaca.

Bourdieu P. (2015). El sentido social del gusto: Elementos para una sociología de la cultura. México: Siglo XXI Editores.

Cauquelin A. (2015). Desde el ángulo de los mundos posibles. Buenos Aires: Adriana Hidalgo Editora.

Clark, T. (2000). Arte y propaganda en el siglo XX. Madrid: Akal. 
De Candé R. (2002). Nuevo diccionario de la música, vol. I y II. Barcelona: Grasindo.

Fuchs W., en Hatje Ursula. (2005). Historia de los Estilos Artísticos I. Desde la Antigüedad hasta el Gótico. Madrid: Ediciones Istmos S.A.

Fundación Juan March. (2007) Roy Lichtenstein, de principio a fin [cat. expo. Madrid]. Madrid: Fundación Juan March.

Galería Enrico Navarra. (2000). Catálogo razonado de la obra de Jean Michel Basquiat [Vol. 1, 2 y 3]. Paris.

Giedion, S. (1978). La mecanización toma el mando. Barcelona: Gustavo Gilli.

Gombrich E.H. (2010) Gombrich Esencial. Textos escogidos sobre arte y cultura. Londres: Phaidon Editores.

González Ochoa, C. y Torres Amaya, R. (2012) Diseño y consumo en la sociedad contemporánea. México: Designio.

Granés, C. (2011). El puño invisible. México: Penguin Random House.

Hatje U. (2005). Historia de los estilos artísticos I. Desde la Antigüedad hasta el Gótico. Madrid: Ediciones Istmos S.A.

Higuera-Trujillo, J., L., Llinares, C., y Macagno, E. (2021). The Cognitive-Emotional Design and Study of Architectural Space: A Scoping Review of Neuroarchitecture and Its Precursor Approaches. Sensors, 21(6), 2193. https://doi. org/10.3390/s21062193

Ishai, A., Fairhall, S.L. y Pepperell, R. (2007). Perception, memory and aesthetics of indeterminate art. Brain Research Bulletin, 73, pp. 319-324. https://doi. org/10.1016/j.brainresbull.2007.04.009

Jacobs, J. (1961) Muerte y vida de las grandes ciudades. Madrid: Capitán Swing. 
Lampkin F. (2017). Bandera: Johns eleva a arte un cacho de trapo combustible dispuesto a arder para iluminar el nombre de cualquier mierdaseca. Recuperado de https:/historia-arte.com/obras/bandera-johns

Lefebvre, H. (1968). La vida cotidiana en el mundo moderno. Madrid: Alianza Editorial.

McElroy, W. (1998). La ignorancia humana y la ingeniería social. Oakland: The independent institute.

Marinetti, T. F. (1909). Manifiesto futurista. Periódico Le Fiigaro, Francia, 20 de Febrero de 1909.

Marinetti, T. F. (1978). Manifiestos y textos futuristas. Barcelona: Ediciones del Cotal.

Marks, B. R. (2007). Los orígenes del mundo moderno. Una nueva visión. Barcelona: Editorial Crítica.

Moreno, L. (2004) Propiedades de los colores. Recuperado de https://desarrolloweb. com/articulos/1503.php

Norman, D. (2005). El diseño emocional: por qué nos gustan (o no) los objetos cotidianos. Madrid: Paidós Ibérica.

Printz, N. y King-Nero, S. (2010). Andy Warhol, Catálogo Razonado Vol. 3. New York: Phaidon Editores.

Portero, F. (2001). La CIA y la Guerra Fría cultural. Recuperado de http://www. elcultural.com/revista/ letras/la-ciA-y-la-guerra-fria-cultural/1703.

Ruiz, N. (2020) Action painting, Pollock y moda. Recuperado de https://www.dsigno. es/blog/diseno-de-moda/action-painting-pollock-y-moda

Sánchez, M. (2018) Basquiat: Biografía, obras y exposiciones. Recuperado de https:// www.alejandradeargos.com/index.php/es/completas/32-artistas/41613-basquiat-biografia-obras-y-exposiciones 
Smil, V. (2005). Creating the Twentieth Century: Technical Innovations of 1867-1914 and Their Lasting Impact. Oxford: Oxford university press.

Stonor, F. (2001). La CIA y la guerra fría cultural. Barcelona: Editorial Debate.

Valèry, P. (2019). Sur l'art- La conquête de l'ubicuité. París: Ed. Edilivre

Valmaseda, C. (2011). Dziga Vertov y los trenes de agitación (1919-1921). Recuperado de http://cinesovietico.com/?p=1904.

Vázquez, R. G. (2013). El cuanto de diseño: Nodo de configuración entre el imaginario y la ciudad red. En Ciudades red: una visión a través de los imaginarios urbanos. Guadalajara: Editorial Universidad de Guadalajara.

Vázquez, R. G. (2015). Apuntes sobre Arte, Diseño e ingeniería Social. Monterrey: Tilde Editores.

Rodríguez, G. V. (2019). Fundamentos de la sociedad y la ciudad de consumo. Señalamiento a sus dinámicas habituales. Contexto. Revista de la Facultad de Arquitectura de la Universidad Autónoma de Nuevo León, 13(18), 31-43.

Virilio, P. (1978). Defensa popular y luchas ecológicas. París: Lèspace critique. 
Declaración de la contribución de autores y colaboradores

\begin{tabular}{|l|l|}
\hline Rol de Contribución & Autor (es) \\
\hline Conceptualización & Gerardo Vázquez Rodríguez \\
\hline Análisis formal & Gerardo Vázquez Rodríguez \\
\hline Investigación & Gerardo Vázquez Rodríguez \\
\hline Discusión de los resultados & Gerardo Vázquez Rodríguez \\
\hline $\begin{array}{l}\text { Revisión y aprobación de la } \\
\text { versión final }\end{array}$ & Gerardo Vázquez Rodríguez \\
\hline
\end{tabular}

